LAPORAN KASUS

\title{
Operasi Payudara dengan Anestesi Spinal Lumbar
}

\section{Breast Surgery Under Lumbar Spinal Anaesthesia}

Mohammad Sudrajat ${ }^{{ }^{*}}$, Moh. Sofyan Harahap ${ }^{* *}$, Doso Sutiyono ${ }^{* *}$

*Resident of Anesthesiology and Intensive Theraphy, Faculty of Medicine, Diponegoro University/Dr. Kariadi Hospital

${ }^{* *}$ Department of Anesthesiology and Intensive Care, Diponegoro University/Dr. Kariadi Hospital

${ }^{\triangle}$ Correspondence/ Korespondensi : mohsudrajat@gmail.com

\begin{abstract}
ABSTRACK
General anaesthesia is a choice of anaesthesia for breast surgeries like mastectomy. However, patients with lung metastases, poor pulmonary function are at a high risk for perioperative mortality and morbidity because of pulmonary complications under general anaesthesia. Alternative technique of anaesthesia should be considered for patient with pulmonary problems, such as metastases of tumor and atelectasis, as well as for patient who reject the general anaesthesia. Lumbar spinal anaesthesia, one of simple and wellknown technique, could be taken as alternative for breast Surgery. We reported three cases of breast surgery under lumbar spinal anaesthesia, without any adverse reaction/problem, and patients are satisfy with the technique applied.
\end{abstract}

Keywords: spinal anaesthesia; breast surgery; regional anaesthesia

\begin{abstract}
ABSTRAK
Anestesi umum adalah pilihan anestesi untuk operasi payudara seperti mastektomi. Namun, pasien dengan metastasis paru, fungsi paru yang buruk memiliki risiko tinggi untuk mortalitas dan morbiditas perioperatif karena komplikasi paru akibat anestesi umum. Teknik alternatif harus dipertimbangkan untuk pasien dengan masalah paru, seperti metastasis tumor dan atelektasis, serta untuk pasien yang menolak prosedur anestesi umum. Anestesi spinal, salah satu teknik sederhana dan terkenal, bisa diambil sebagai alternatif untuk operasi payudara. Kami melaporkan tiga kasus operasi payudara dengan anestesi spinal lumbal, tanpa reaksi / masalah yang merugikan, dan pasien puas dengan teknik yang diterapkan.
\end{abstract}

Kata Kunci: anestesi spinal; operasi payudara; an estesi regional

Volume X, Nomor 1, Tahun 2018

Terakreditasi DIKTI dengan masa berlaku 3 Juli 2014 - 2 Juli 2019

Dasar SK Menteri Pendidikan dan Kebudayaan RI Nomor 212/P/2014 


\section{PENDAHULUAN}

Kanker payudara adalah kanker yang paling sering didiagnosis pada wanita. ${ }^{1}$ Akibatnya, kebutuhan untuk perawatan bedah semakin meningkat. Saat ini, intervensi pembedahan lebih konservatif, tetapi dalam banyak kasus, mastektomi parsial atau total masih dibutuhkan. ${ }^{2}$ Anestesi umum adalah teknik konvensional yang digunakan pada operasi payudara. Operasi payudara dikaitkan dengan insiden nyeri paska operasi yang tinggi. Diperkirakan bahwa lebih dari $50 \%$ wanita menderita nyeri kronis setelah operasi kanker payudara. Anestesi regional merupakan alternatif yang baik untuk anestesi umum pada operasi kanker payudara, memberikan analgesia superior dan efek samping lebih sedikit yang berhubungan dengan analgesia berbasis opiat. Anestesi regional menurunkan stres operatif, memberikan efek hemodinamik yang menguntungkan terutama untuk pasien sakit kritis, dan menurunkan morbiditas dan mortalitas paska operasi. Selain itu, juga mengurangi mual dan muntah paska operasi, dan memberikan blok sensorik paska operasi yang berkepanjangan, meminimalkan kebutuhan obat narkotika. ${ }^{3}$ Ada berbagai penelitian yang membandingkan spinal thoraks atau segmental dengan anestesi umum. Anestesi regional adalah teknik unik pada operasi mastektomi kondisi sadar. Perhatian harus dilakukan pada kenyamanan, keamanan, sedikit komplikasi, dan mengurangi morbiditas dibandingkan anestesi umum. ${ }^{4}$ Kami menyajikan 3 kasus manajemen anestesi yang berhasil pada wanita yang didiagnosis dengan tumor payudara, dengan anestesi spinal lumbal sebagai teknik anestesi untuk operasi payudara.

\section{KASUS}

Ada tiga kasus kanker payudara yang akan menjalani operasi di RSUP Dr. Kariadi pada bulan Mei 2018. Kasus 1 : wanita berusia 56 tahun menjalani mastektomi, karena kanker payudara kanan dengan metastase paru dan atelektasis. Kasus 2 : wanita 32 tahun menjalani eksisi luas, karena tumor phylloides pada payudara kiri. Kasus 3: Wanita berusia 59 tahun menjalani prosedur singkat insisi lebar dan biopsi, atas indikasi kanker payudara kanan dengan metastase paru, atelektasis dan efusi pleura.

Semua pasien didiagnosis dan disiapkan melalui klinik onkologi, dan setelah semua pemeriksaan pra operasi selesai, pasien dirawat di bangsal untuk persiapan operasi. Data perioperatif lengkap dari semua pasien ditunjukkan pada Tabel 1.

Konseling pra-operasi telah dilakukan akukan dan persetujuan tindakan tertulis telah disetujui dan pasien dengan status ASA II-III. Pasien diberikan informasi dan mendapatkan persetujuan jika dalam pembiusan anestesi regional spinal gagal atau sampai mengganggu pernapasan dan kesadarannya akan dilakukan anestesi umum. Pada pasien yang ditemukan masalah dalam pemeriksaan fisik atau penunjang akan dioptimalkan dan berkolaborasi dengan lintas bidang keahlian seperti internist dan cardiologist. Kami berdiskusi dengan pasien-pasien ini tentang teknik anestesi spinal lumbal 
sebagai alternatif, dan setelah mendapatkan persetujuan dari pasien dan keluarga, kami menyiapkan pasien serta obat-obatan anestesi dan alat untuk mencegah komplikasi.

Pada pemeriksaan jalan napas, edentulous pasien dapat membuka mulut dengan ukuran tiga jari, dengan jarak thyro-mental $6 \mathrm{~cm}$, dan pasien memiliki gerakan sendi leher dan tympano-mandibula yang normal. Pemeriksaan tulang belakang normal. Pemeriksaan laboratorium seperti tes darah rutin, kadar gula darah, elektrolit, tes fungsi ginjal dan profil koagulasi berada dalam kisaran normal. Pasien diberikan cairan I.V Ringer Laktat.

Pasien didorong masuk ke ruang operasi. Pemantauan termasuk 3-lead electrocardiogram, pulse oximetry, dan tekanan darah non-invasif. Akses intravena diperoleh dengan menggunakan IV-kateter18G pada ekstremitas atas dan diberikan cairan intravena, yaitu Ringer laktat $500 \mathrm{ml}$ sebelum anestesi spinal lumbal dilakukan. Profilaksis anti-aspirasi diberikan Inj. Ranitidine (50 $\mathrm{mg}$ ) dan Inj. Metoclopramide (10 mg). Inj. Midazolam (1 mg) diberikan untuk mengurangi kecemasan. Oksigen diberikan melalui kanula nasal dengan laju aliran 3 liter per menit. Meja operasi bagian kepala diturunkan dengan sudut sekitar $15-20^{\circ}$ dengan sisi yang sakit berada dibawah (misalnya lateral kiri untuk mastektomi kiri). Blok sub-arachnoid unilateral diberikan dalam posisi lateral kanan atau kiri (tergantung pada payudara yang akan dioperasi) dengan pendekatan midline dengan jarum spinal berukuran $25-27 \mathrm{G}$ di L2-L3 / L3-4, dengan 2,5 $\mathrm{ml}$ bupivacaine
$0.5 \%$ heavy dan adjuvan fentanyl $25 \mathrm{mcg}$ $(0,5 \mathrm{ml})$, setelah dipastikan dengan jelas dan aliran bebas cairan serebrospinal dan aspirasi darah negatif. Obat-obatan diberikan sangat lambat selama 2-2,5 menit. Dermatom diperiksa sampai setinggi T2, kemiringan meja operasi dikoreksi setelah tinggi blok yang diharapkan tercapai. Pasien dipertahankan dalam posisi lateral selama 10 menit setelah itu pasien terlentang untuk meminimalkan risiko blok spinal tinggi atau total spinal. Tingkat anestesi yang adekuat dicapai hingga level T2. Semua prosedur seperti pada gambar 1 . Memonitoring terus menerus pada respirasi, tekanan darah, denyut jantung, SpO2, dan tingkat kesadaran. Oksigen diberikan selama prosedur. Data intraoperatif lengkap dari semua pasien ditunjukkan pada Tabel 2.

Durasi operasi berkisar 1-1,5 jam, dengan kehilangan darah 100-250 $\mathrm{ml}$ dan output urin 100-150 ml. 500-1000 ml kristaloid (ringer's lactate) diberikan sepanjang prosedur. Untuk analgesia paska operasi, ketorolac $30 \mathrm{mg}$ dan parasetamol 1000 mg diberikan. Paska operasi, pasien diamati di post anaesthesia care unit $(P A C U)$ selama 2 jam. Di $P A C U$, pasien tidak mengeluh nyeri, sesak, nyeri kepala, mual / muntah dan dysaesthesia lengan atau tangan atau kelumpuhan. (Gambar 1)

\section{DISKUSI}

Anestesi umum saat ini adalah teknik standar yang digunakan untuk tindakan bedah kanker payudara. Kekurangan anestesi umum, tetapi tidak terbatas pada, kontrol nyeri karena kurangnya analgesia, insidensi mual dan 
Table 1. Karakteristik pasien dan data perioperatif

\begin{tabular}{|c|c|c|c|c|c|c|c|c|c|}
\hline \multirow[b]{2}{*}{$\begin{array}{l}\text { No. } \\
\text { Kasus }\end{array}$} & \multirow[b]{2}{*}{$\begin{array}{c}\text { Usia } \\
\text { (tahun) } \\
/ \text { jenis } \\
\text { kelamin }\end{array}$} & \multirow[b]{2}{*}{$\begin{array}{c}\text { Tinggi (cm) } \\
\text { / Berat } \\
\text { Badan (kg)/ } \\
\text { Diagnosis / } \\
\text { Tindakan }\end{array}$} & \multicolumn{4}{|c|}{ Hemodinamik Perioperatif } & \multirow[b]{2}{*}{$\begin{array}{c}\text { Problem } \\
\text { fisik }\end{array}$} & \multirow[b]{2}{*}{ EKG } & \multirow[b]{2}{*}{ X-ray Thorax } \\
\hline & & & $\begin{array}{l}\text { SBP/ } \\
\text { MAP } \\
(\mathbf{m m} \\
\mathbf{H g})\end{array}$ & $\begin{array}{c}\text { HR } \\
\text { (per } \\
\text { men) }\end{array}$ & $\begin{array}{c}\text { RR } \\
\text { (per } \\
\text { men) }\end{array}$ & $\begin{array}{c}\mathrm{T} \\
\left({ }^{\circ} \mathrm{C}\right)\end{array}$ & & & \\
\hline 1 & $56 / \mathrm{W}$ & $\begin{array}{l}\text { 156/63/ } \\
\text { Kanker } \\
\text { payudara } \\
\text { kanan/ } \\
\text { Mastektomi }\end{array}$ & $\begin{array}{c}126 / \\
72\end{array}$ & 84 & 18 & 36,7 & $\begin{array}{l}\text { Penurun- } \\
\text { an suara } \\
\text { vesikular } \\
\text { pada } \\
\text { paru } \\
\text { kanan }\end{array}$ & NSR & $\begin{array}{l}\text { Nodul paru } \\
\text { pada } \\
\text { lapangan } \\
\text { tengah paru, } \\
\text { matastasis } \\
\text { tumor. } \\
\text { Atelektasis }\end{array}$ \\
\hline 2 & $32 / \mathrm{W}$ & $\begin{array}{l}\text { 145/46/ } \\
\text { Kanker } \\
\text { payudara, } \\
\text { Tumor } \\
\text { Phyloides } \\
\text { payudara } \\
\text { kiri/ } \\
\text { Eksisi luas }\end{array}$ & $\begin{array}{c}120 / \\
70\end{array}$ & 75 & 14 & 36,4 & None & NSR & $\begin{array}{lr}\text { Jantug dan } \\
\text { paru dalam } \\
\text { batas } \\
\text { normal }\end{array}$ \\
\hline 3 & $55 / \mathrm{W}$ & $\begin{array}{l}155 / 57 / \\
\text { Kanker } \\
\text { payudara } \\
\text { kanan/Insisi } \\
\text { luas dan } \\
\text { biopsi }\end{array}$ & $\begin{array}{c}110 / \\
68\end{array}$ & 82 & 20 & 37 & $\begin{array}{l}\text { Penurun } \\
\text { an suara } \\
\text { vesikular } \\
\text { pada } \\
\text { paru } \\
\text { kanan }\end{array}$ & $\begin{array}{l}\text { Sinus } \\
\text { taki- } \\
\text { kardia }\end{array}$ & $\begin{array}{l}\text { Nodul paru } \\
\text { pada } \\
\text { lapangan } \\
\text { tengah dan } \\
\text { basal paru } \\
\text { kanan, } \\
\text { matastasis } \\
\text { tumor. } \\
\text { Efusi pleura } \\
\text { Atelektasis. }\end{array}$ \\
\hline
\end{tabular}

Singkatan: W (Wanita), SBP (Systolic Blood Pressure), MAP (Mean Arterial Pressure), $H R$ (Heart Rate), RR (Respiratory Rate), $T$ (Temperature), ECG (Electrokardiografi), NSR (Normo Sinus Rhytm) 
Tabel 2. Data intraoperatif

\begin{tabular}{cccccccccc}
\hline \multicolumn{1}{c}{ Tanda vital } & & & \multicolumn{3}{c}{ Efek merugikan } \\
\hline $\begin{array}{c}\text { No. } \\
\text { kasus }\end{array}$ & SBP & DBP & MAP & HR & RR & SpO2 & Gangguan & Mual/ & $\begin{array}{c}\text { Dysaesthe- } \\
\text { sia/ paralisis } \\
\text { lengan / } \\
\text { tangan }\end{array}$ \\
\hline 1. & $122 / 110$ & $86-70$ & $68-70$ & $70-80$ & $14-16$ & $99-100$ & none & none & none \\
\hline 2. & $120 / 116$ & $80-68$ & $64-69$ & $62-72$ & $12-14$ & $99-100$ & none & none & none \\
\hline 3. & $126 / 109$ & $82 / 72$ & $68-70$ & $64-70$ & $12-16$ & $99-100$ & none & none & none \\
\hline
\end{tabular}

Singkatan: SBP (Systolic Blood Pressure), DBP (Diastolic Blood Pressure), MAP (Mean Arterial Pressure), HR (Heart Rate), RR (Respiratory Rate)

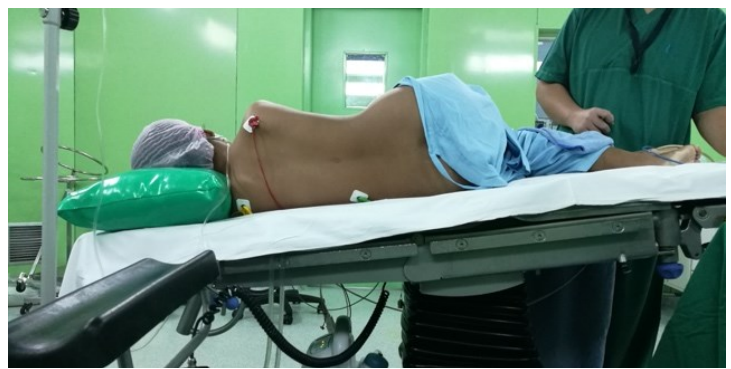

Gambar 1: Posisi kepala 15-20 derajat kebawah

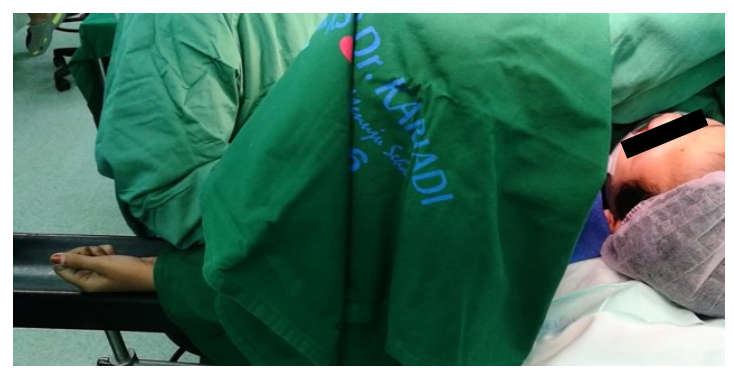

Gambar 3: pasien merasa nyaman

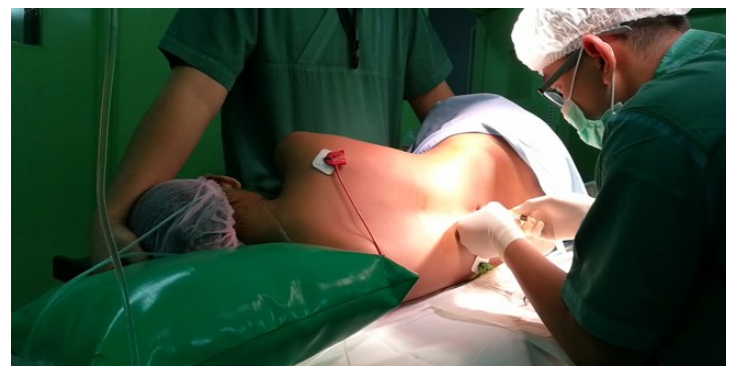

Gambar 2: Prosedur anestesi spinal lumbar

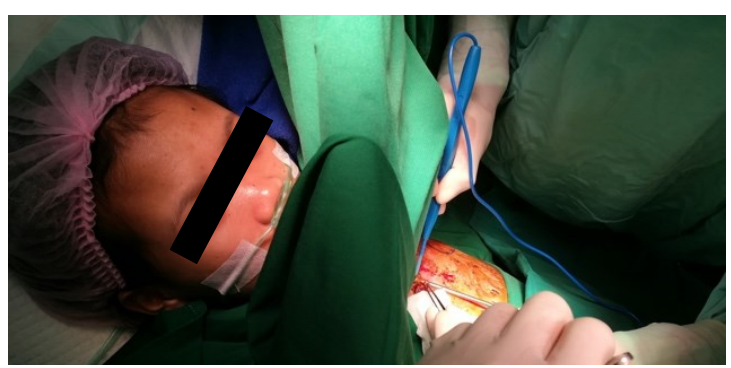

Gambar 4: prosedur operasi payudara

Gambar 1. Prosedur operasi payudara dengan anestesi spinal lumbar 
muntah yang tinggi dan meningkatkan lama rawat inap . ${ }^{2}$

Nitin C Kotwat $^{4}$ menjelaskan penggunaan anestesi spinal lumbar untuk operasi radikal mastektomi. Tusukan dilakukan antara vertebra lumbar ke-3 dan ke-4, yang menghasilkan analgesia yang baik untuk operasi mastektomi tanpa efek pada otot pernapasan yang dapat menyebabkan kesulitan bernapas.

Anestesi regional seperti anestesi spinal atau epidural telah ditetapkan sebagai manajemen perioperatif untuk bedah toraks, abdomen dan ekstremitas bawah dengan manfaat klinis pemulihan lebih cepat, analgesia yang efektif dan hasil yang lebih baik. Selain itu, anestesi neuraksial dapat menghambat respon stres neuro-endokrin dan pasien yang dilakukan analgesia regional memiliki kebutuhan opioid yang lebih rendah. ${ }^{2}$

Mastektomi radikal dengan anestesi spinal adalah teknik yang sederhana, aman dan hemat biaya. Di era anestesi regional saat ini, ini dapat dipraktekkan dengan sangat baik.

Kelebihan:

1. Tidak diperlukan keahlian khusus karena prosedurnya identik dengan anestesi spinal.

2. Dapat dipraktekkan dengan baik di daerah perifer dengan fasilitas minimal.

3. Tidak ada kontraindikasi absolut kecuali untuk anestesi spinal.

4. Mengurangi komplikasi intraoperatif dan pakca-operasi.

5. Morbiditas berkurang.

6. Bermanfaat untuk pasien, kepuasan dan kenyamanan dokter bedah. ${ }^{4}$
Spinal tinggi atau total merupakan komplikasi anestesi spinal yang dapat terjadi. Istilah "lengkap" atau "total" mengindikasikan blok anestesi yang melibatkan tulang servikal dan diatasnya (seperti batang otak dan saraf kranial). Evidence menunjukkan bahwa factor risiko pasien yang terkait dengan spinal tinggi atau total pada Tabel 3. Manifestasi klinis dari total spinal termasuk beberapa atau semua ada pada Tabel 4. Insiden total spinal tidak diketahui. Ada banyak laporan kasus dan serangkaian kasus yang terbatas dari komplikasi ini akibat anestesi spinal. Studi di Inggris dan Perancis terbatas pada kardio-respirasi yang fatal setelah dilakukan anestesi spinal. Jika total spinal diasumsikan menjadi penyebab semua peristiwa ini maka ekstrapolasi data ini akan menunjukkan insidensi total spinal $<1 /$ 100.000 hingga $27 / 100.000(0,001-$ $0,027 \%)^{5}$ (Tabel 3) (Tabel 4)

Pasien kanker payudara dengan metastasis paru, efusi pleura dan atelektasis harus mempertimbangkan faktor risiko morbiditas dan mortalitas karena komplikasi paru. Komplians paru secara merata berkurang pada semua pasien dengan metastasis limfangitik difus. Pada subjek dengan multiple metastasis hematogen, penurunan komplians paru berkaitan dengan keterlibatan jaringan tumor. Beberapa metastasis hematogen menyebabkan hipoksemia karena mekanisme seperti shunt; metastasis lymphangitic difus menurunkan oksigenasi karena efeknya pada area pertukaran gas di paru-paru. ${ }^{6}$ Agen anestesi umum, opiod, relaksan otot dan ventilasi mekanis mengganggu fungsi pernapasan. Pasien-pasien ini sulit 
disapih dari ventilator dan mungkin memerlukan ventilasi yang lama paska operasi. Pasien yang menjalani operasi payudara juga biasanya dikaitkan dengan tingginya insiden mual dan muntah paska operasi (PONV). Nyeri dan PONV dapat memperpanjang pemulihan dan rawat inap. Blok regional memiliki insidensi mual dan muntah yang lebih rendah, bila dibandingkan dengan anestesi umum, yang telah dibuktikan dalam beberapa prosedur dan studi. ${ }^{7}$

Pasien yang akan menjalani prosedur bedah dan menolak prosedur anestesi umum juga harus dipertimbangkan tentang keputusan pasien. Kita tidak boleh melanggar apa yang telah menjadi keputusan pasien atau keluarganya. Setiap prosedur, teknik, keuntungan, kerugian dan risiko medis yang mungkin terjadi telah dijelaskan. Dalam hal ini, informed consent sangat diperlukan. Informed consent adalah instrumen hukum yang memungkinkan individu untuk menentukan kepentingan mereka sendiri dan untuk melindungi privasi atas tubuh mereka. ${ }^{8}$ Sebagian besar pasien yang menjalani operasi mengalami ketakutan akan anestesi. Sebagian besar wanita memiliki risiko lebih tinggi untuk takut. Ketakutan dapat membawa kecemasan, yang pada akhirnya, dapat mempengaruhi operasi pasien. ${ }^{9}$ Blok regional adalah teknik anestesi yang tidak menyebabkan hilangnya kesadaran kecuali terjadi komplikasi.

Oleh karena itu, dalam kasus pasien kami, yang menderita kanker payudara dengan metastasis paru, efusi pleura dan atelektasis serta pasien dengan kanker payudara yang lebih memilih untuk menjalani operasi payudara, kami merencanakan prosedur anestesi spinal lumbar sebagai teknik anestesi yang memberikan keamanan dan analgesia dengan kondisi pembedahan yang meningkat.

Tabel 3. Faktor resiko untuk spinal tinggi/total

1. Epidural sebelumnya (terutama "top up")

2. Dosis obat anestesi lokal yang besar

3. Posisi supine yang cepat

4. Peningkatan tekanan intra-abdomen (termasuk kehamilan dan obesitas) ${ }^{5}$

Tabel 4. Manifestasi klinis total spinal

\begin{tabular}{ll}
\hline Kardio-respirasi & Neurologikal \\
\hline Hipotensi & Mual dan kecemasan \\
Bradikardia & Disnestesia lengan atau tangan atau kelumpuhan \\
Gangguan pernapasan & Blok level sensorik yang tinggi \\
Apnea & Keterlibatan saraf kranial \\
Penurunan saturasi oksigen & Kehilangan kesadaran \\
\hline
\end{tabular}




\section{KESIMPULAN}

Anestesi regional seperti anestesi spinal lumbar adalah salah satu pilihan yang lebih baik dalam teknik anestesi untuk prosedur mastektomi dengan masalah paru dan pembedahan payudara tanpa kehilangan kesadaran. Anestesi spinal lumbar juga memberikan kualitas baik untuk analgesia intra / paska operasi dan dapat menurunkan kejadian mual dan muntah paska-operasi (PONV).

\section{DAFTAR PUSTAKA}

1. Solikhah S, Promthet S, Rakkapao N, Hurst CP. Validation of an Indonesian Version of the Breast Cancer Awareness Scale (BCAS-I). Asian Pac J Cancer Prev. 2017;18(2):515-22.

2. M GM, B KU, R DP. Unilateral Spinal Anaesthesia For Toilet Mastectomy-As An Alternative To General Anaesthesia: A Case Report. 2015;3(32):12-4.

3. Mazy A, Mazy A. Thoracic Spinal Anesthesia in Awake Breast Surgery. 2017;

4. Rajappa SA, Shaji J. Radical Mastectomy under Lumbar Spinal Anaesthesia. Vol.6, International Journal of Biomedical Research. 2015.

5. Newman B, Registrar A, Hospital RH. Complete Spinal Block Following Spinal Anaesthesia Anaesthesia Tutorial of the Week 180. 2010; (May):1-4.

6. Popper HH. Progression and metastasis of lung cancer. Cancer Metastasis Rev. 2016;35(1):75-91.

7. Borgeat A, Ekatodramis G, Schenker C. Postoperative nausea and vomiting in regional anesthesia: a review. Anesthesiology [Internet]. 2003;
(2):530-47. Available from: http://journals.lww.com/ anesthesiology/Abstract/2003/02000 Postoperative Nasea_and_Vomiting_in_Regional.36. aspx

8. White SM. Consent for anaesthesia. J Med Ethics. 2004;30(3):286-90.

9. Ruhaiyem ME, Alshehri AA, Tawfeeq NA. Fear of going under general anesthesia: A cross-sectional study Abstract Objectives: Materials and Methods : Results : Conclusion : 